\title{
PERCEPÇÃO AMBIENTAL COMO ESTRATÉGIA DE INVESTIGAÇÃO EM ARQUITETURA: UM ESTUDO DE CASO
}

\author{
PERCEPCIÓN AMBIENTAL COMO ESTRATEGIA DE INVESTIGACIÓN EN ARQUITECTURA: UN ESTUDIO \\ DE CASO
}

ENVIRONMENTAL PERCEPTION AS A RESEARCH STRATEGY IN ARCHITECTURE: A CASE STUDY

NIEMEYER, CARLOS AUGUSTO DA COSTA

Doutor, Professor efetivo do IFSP, email: carlosniemeyer@hotmail.com

\section{RESUMO}

O estudo busca levantar a percepção ambiental de uma escola secundária sob o ponto de vista do olhar e da vivência da sua comunidade discente. Trata-se de um estudo de caso sobre percepção ambiental adotando-se a metodologia de "atributos induzidos" também conhecida pela ferramenta "constelação de atributos". Introduz questões afetas a psicologia ambiental e suas decorrentes relações de análise comportamentais geradas a partir dos aspectos físicos e sensoriais de organização do ambiente construído. Para o desenvolvimento desse estudo foram realizadas entrevistas com alunos de duas turmas de design de interiores, sendo estimulados sua percepção cognitiva com base em perguntas-chave endereçadas pelo pesquisador conforme sugere o modelo teórico. Apresenta padrões gráficos - constelação de atributos - que permitem identificar e qualificar atributos ligados a percepção do ambiente. Os resultados gerados permitem demonstrar graficamente os atributos levantados de maior relevância e assim mapear o nível de percepção cognitiva de conforto que o ambiente escolar oferece a seus usuários.

PALAVRAS-CHAVE: Percepção Ambiental; Constelação de Atributos; Pesquisa em Arquitetura

\section{RESUMEN}

El estudio busca levantar la percepción ambiental de una escuela secundaria desde el punto de vista de la mirada y la vivencia de su comunidad discente. Se trata de un estudio de caso sobre percepción ambiental adoptando la metodología de "atributos inducidos" también conocida por la herramienta "constelación de atributos". Introduce cuestiones afines a la psicología ambiental y sus derivadas relaciones de análisis comportamentales generadas a partir de los aspectos físicos y sensoriales de organización del ambiente construido. Para el desarrollo de este estudio se realizaron entrevistas con alumnos de dos clases de diseño de interiores siendo estimulados su percepción cognitiva con base en preguntas clave dirigidas por el investigador conforme sugiere el modelo teórico. Presenta patrones gráficos constelación de atributos - que permiten identificar y calificar atributos ligados a la percepción del ambiente. Los resultados generados permiten demostrar gráficamente los atributos planteados de mayor relevancia y asi mapear el nivel de percepción cognitiva de confort que el ambiente escolar ofrece a sus usuarios. PALABRAS CLAVES: Percepción ambiental; Constelación de Atributos; Búsqueda en Arquitectura

\section{ABSTRACT}

The study seeks to raise the environmental perception of a secondary school from the point of view of the look and experience of its student community. It is a case study about environmental perception adopting the methodology of "induced attributes" also known by the graphic model "constellation of attributes". It introduces issues related to environmental psychology and its associated behavioral analysis relationships generated from the physical and sensory aspects of the organization of the built environment. For the development of this study, interviews were conducted with students from two interior design classes who were stimulated in their cognitive perception based on key questions addressed by the researcher as suggested by the theoretical model. It presents graphic patterns - constellation of attributes - that allow to identify and qualify attributes linked to the perception of the environment. The generated results allow graphically demonstrating the attributes raised of greater relevance in the cognitive perception of comfort that the school environment offers its users. KAYWORDS: Environmental perception; Constellation of Attributes; Architecture Research

\section{INTRODUÇÃO}

O planejamento de equipamentos urbanos comunitários (educação, cultura, saúde, lazer e assemelhados), assim definido pela Lei Federal no. 6.766/79 (Art. 4ํp. parag. 20), artefatos concebidos pelo poder público e que abarcam escolas públicas, é um fator determinante para garantia do bem-estar social, prover socialização e apoio ao desenvolvimento econômico local e regional.

No ponto de vista conceitual, as profundas modificações metodológicas no campo disciplinar da arquitetura, resultado da baixa resposta ambiental da abordagem racionalista, retomou o ideário humanista centrado na recuperação de abordagens multidisciplinares, como a análise visual e a percepção ambiental, que voltaram a despertar interesse nas decisões de projeto na arquitetura contemporânea (MONTANER, 1993). Assim, a recuperação de padrões ambientais e estéticos que restaurassem a experiência perceptiva e emocional 
passou a angariar profunda importância na práxis arquitetônica contemporânea, vinculando-se a qualidade do ambiente construído.

O teórico italiano Bruno Zevi (1977) destaca o protagonismo do espaço arquitetônico como algo que vai muito além da concretude espacial, mas que possua um "espaço interior" cheio de intenções que não se pode alcançar sem envolver-se numa intensa experiência de percepção e apropriação. É nesse contexto de valorização da experiência do lugar tão demarcada na arquitetura que se introduz a abordagem da percepção e da cognição ambiental. Compreender sua influência no processo relacional pessoa-ambiente possibilita o reconhecimento de elementos que funcionam como condicionantes do bem-estar subjetivo dos sujeitos que interagem com os espaços, sejam públicos ou privados, abertos ou fechados. O espaço, segundo Zevi (op. cit, p. 18) só pode ser "conhecido e vivido a não ser pela experiência direta" e, dessa maneira, nos subjugando emocionalmente, razão essa determinante para a existência da própria arquitetura.

Diversas teorias construídas a partir dos anos 1950 enriqueceram a compreensão do ambiente vivido a partir de análises de interpretações cognitivas iluminando fenômenos comportamentais que fundamentaram a chamada teoria do behavior setting (BARKER, 1968) com profundas implicações em estudos subsequentes afetos a percepção do ambiente construído. A esta base conceitual, acrescentaram-se, todavia, outros fundamentos que ampliaram o conhecimento das interrelações pessoa-ambiente calcadas na compreensão de sentimentos de apego e afetividade ao lugar (TUAN, 1980).

Assim emergiu a psicologia ambiental, disciplina que reúne esses predicados teóricos, sendo uma área aplicada da ciência psicológica à análise do ambiente construído cujo objetivo é entender aspectos relacionais entre o sujeito e seu ambiente e como isso pode impactar nosso comportamento face as respostas sensoriais e emocionais geradas por esta interface. Perfaz uma interação cognitiva entre o indivíduo e o contexto ambiental em que habita, e que define a forma como o percebemos, sentimos e agimos (DEL RIO; DUARTE; RHEINGANTZ, 2002; CORRAL-VERDUGO, 2005; FONSECA; RHEINGANTZ, 2009).

O estudo de caso, aqui oferecido, pretende demonstrar uma experiência de diagnóstico de percepção ambiental de um microssistema (a escola pública) adotando-se o método de análise denominado de "atributos induzidos" e seu modelo gráfico - a "constelação de atributos" - que vem sendo aplicada em análises ambientais no campo da arquitetura e do design de interiores no interesse de apreender a chamada "consciência psicológica" do usuário (MONT'ALVÃO; VILAROUCO, 2011; VASCONCELOS. et al, 2010). Voltada à análise e apreensão do espaço de vivência, o método constitui uma lente investigativa em um contexto de uma avaliação pós-ocupacional do ambiente físico do campus Jacareí do Instituto Federal de São Paulo (IFSP). O estudo foca a análise da qualidade vivencial buscando levantar atributos (positivos ou negativos) que venham a qualificar sua usabilidade, assim procurando dimensionar os atributos dessa relação a partir do ponto de vista dos alunos, auxiliando os arquitetos na gestão do projeto.

\section{REFERENCIAL TEÓRICO}

O notável educador Anísio Teixeira (1900-1971), protagonista das grandes mudanças que ocorreram na educação brasileira no século XX, considerado um pioneiro na implantação de escolas públicas que refletiam o ideário progressista de uma educação integral laica, gratuita e de qualidade, também defendeu com entusiasmo os ideais inovadores da então florescente arquitetura moderna. Devotado defensor da associação dos princípios construtivos modernos com idealismo social proposto aos programas arquitetônicos, Anísio tinha em mente que a qualidade do espaço flexível moderno "integrado à natureza" atuasse positivamente no aprendizado, o que determinou grandes mudanças no conceito programático dos novos edifícios escolares no Brasil (BASTOS, 2009).

O valor de uma instituição escolar, aqui considerada enquanto base da formação da cidadania, dá-se fundamentalmente em projetos e propostas pedagógicas que levem em consideração a importância de se valorizar espaços e ambientações que possam influenciar positivamente o comportamento humano. Olhar com atenção à qualidade do ambiente de ensino significa entender como a interferência do espaço físico pode atuar de maneira positiva no processo de aprendizagem de modo que se tornem verdadeiramente ambientes agradáveis à alunos, professores e funcionários (MELO, 2012).

Diversos estudos já revelaram a direta relação entre a qualidade do edifício e o desempenho dos alunos, com positivo impacto na frequência e no comportamento. Atributos de conforto, funcionalidade, sustentabilidade e humanização do ambiente escolar são responsáveis pelo aprimoramento do equipamento escolar, traduzindo-se em profundo bem-estar aos seus ocupantes (KOWALTOWSKI. et al, 2011). Por este aspecto, coloca-se como indispensável a dotação de mecanismos que auxiliem o processo de produção conceitual do projeto na medida da compreensão das demandas de conforto e bem-estar aos usuários. 
Entretanto, a história da construção escolar no Brasil, em que pese notáveis exemplos que revelaram o traço elegante e moderno de obras icônicas, não raro tem sido a de preferência no atendimento à demanda de vagas em detrimento à qualidade ambiental, o que se explica em parte por esbarrar em meandros políticos responsáveis por imposição de limites orçamentários, prazos e recursos estreitos que acabam por amarrar critérios funcionais e ambientais mais sensíveis ao processo de projeto. Um exemplo dessa prática é a ausência de critérios participativos, algo já institucionalizado no país pelo Estatuto das Cidades (Lei Federal no 10.257, de 10 de julho de 2001) e que possibilitaria um debate salutar entre pedagogos, professores e a comunidade atendida que bem poderia gerar perspectivas mais humanizadoras calcada em uma discussão qualitativa no detalhamento dessas obras.

Isso exige reforçarmos a presença da instituição escolar na perspectiva primordial de formação da cidadania, o que vem valorizar a importância de assentarmos critérios humanizadores nos projetos e propostas, entendendo sua influência no comportamento das pessoas que vivem esse ambiente cotidianamente. Assimilar essa interferência positiva aqui vista numa perspectiva freireana de aprendizagem contextualizada às potencialidades do espaço físico e do entorno, abre novos horizontes no planejamento de ambientes escolares, tornando-os ambientes verdadeiramente agradáveis e afetivos. Assim, aspectos relacionais pessoa-ambiente devem ser necessariamente apreendidos no universo de configuração de ambientes escolares, resultando em espaços acolhedores e estimulantes à aprendizagem e a convivência. Melo (2012) fazendo uso do desenho infantil como forma de apreender a percepção ambiental de crianças da rede escolar básica em São Gonçalo (RJ), captou a assimilação de ambientes afetivos domésticos na percepção do ambiente escolar, aqui servindo como exemplo da influência do espaço físico no aprendizado:

Notamos através dos desenhos que os alunos que se identificam com a escola trouxeram elementos de suas casas, diferente das representações dos alunos que não enxergam positivamente o espaço escolar e que o fizeram de forma padronizada e desumanizada, o que comprova a afirmação de que as pessoas quando expostas a espaços desproporcionais sofrem reações psicológicas negativas, o que pode prejudicar seu desenvolvimento educacional (MELO, 2012, XXXI-II).

A escola é um meio ambiente social que, num contexto ideológico, traduz um projeto governamental de futuro para uma sociedade. Coisas importantes acontecem no ambiente escolar, considerado o segundo ambiente mais importante na vida de uma pessoa. Um lugar que deixa de ser apenas um campo de aprendizado e de troca de conhecimentos, mas onde se constrói verdadeiramente uma esfera emocional carregada de envolvimentos afetivos (SOUTO, 2014). As escolas são microcosmos sociais que emulam um "conjunto de conteúdos cognitivos, organizados e rotinizados, pela pedagogia e pela didática, fabricado no contexto educativo, mas projetado para a sociedade" (idem). A importância da escola é inquestionável para o êxito de um processo inicial de sociabilidade.

Assim, se exige de um ambiente escolar um constante repensar nas suas configurações espaciais que possam atender características pedagógicas e funcionais nos contextos locais e temporais para o qual deve manter um forte poder de atratividade e usabilidade de quem o habita. Existindo em geral em boa quantidade nas cidades, as escolas públicas, todavia, nem sempre acomodam boas sensações de apego e afetividade na vivência cotidiana. Tuan (1980) descreve este anseio como "sentimento de topofilia", um elo de afetividade que une pessoa e lugar, conceitos, hoje consagrados nos estudos de psicologia ambiental. Conceitos que envolvem sentidos de pertencimento, atratividade, proteção, segurança, posse e preservação do lugar, e que são fundamentais ao permitirem um estado de conhecimento e apreensão do lugar. Quando associados a relações de pregnância geram, inconscientemente, condições francas de bem-estar que explicam a forte atratividade e apreensão que sentimos em dados lugares, expressão de pura afetividade relacional.

A ambiência, em qualquer situação espacial e escala de abordagem, remete às condições emocionais estimuladas a partir da experiência com o lugar, sendo este considerado humanizado quando reflete um conveniente equilíbrio entre os elementos que compõem o seu espaço físico (BESTETTI, 2014). Elali (1998) ilumina a compreensão desses pressupostos reativos entre comportamento humano $\mathrm{x}$ ambiência a partir de conceitos teóricos inter-relacionados como a percepção ambiental (modo como o indivíduo sente o ambiente), affordance (reconhecimento intuitivo da funcionalidade de um objeto) e comportamento sócio-espacial (capacidade de assimilar o ambiente). A este último, emergem conceitos específicos no contexto da ambiência como espaço pessoal, proxêmica, territorialidade, aglomeração, privacidade, adaptação e apropriação que juntos cooperam, em seu arcabouço teórico, na compreensão dos aspectos emocionais e sensoriais que ocorrem no contexto das interações pessoa-ambiente. 
Todavia quando tais questões não são devidamente apreendidas e trabalhadas em um processo de projeto, a decorrência são respostas superficiais no design arquitetônico desperdiçando a captação mais intensa que as implicações comportamentais podem oferecer na investigação e compreensão do ambiente construído. Assim, no contexto do processo de projeto, constata-se que a incapacidade de percepção, representação e transmissão do objeto arquitetônico, leva inexoravelmente a estruturações espaciais vagas e imprecisas com implicações sérias na qualidade do produto gerado, impondo a necessidade premente de aprimorarmos a gestão do projeto (GRAÇA; KOWALTOWSKI; PETRECHE, 2011; MOREIRA; KOWALTOWSKI, 2011).

A complexidade do processo de projetar demonstra cada vez mais a importância de utilizar métodos específicos, técnicas e ferramentas adequadas de análise e captação informacional gerando formas distintas de envolvimento e tratamento do programa arquitetônico. Abrangendo amplo leque temático interdisciplinar, estudos na linha de pesquisa ambiente-comportamento vêm iluminando a compreensão das dimensões do comportamento humano nas investigações para melhoria da acessibilidade e de percepção do ambiente construído (DEL RIO; DUARTE; RHEINGANTZ, 2002; PINHEIRO; GÜNTHER, 2008).

É nesse pressuposto que se coloca a importância de ferramentas que permitam captar e compreender as respostas físicas e sensoriais das pessoas nos locais que elas convivem ou que pretendam conviver. Partindo do princípio que tais demandas não são facilmente observáveis em face de sua subjetividade e intangibilidade, é necessário a aplicação de métodos específicos que permitam captar e materializar sentimentos e apegos relacionados a propriedades ambientais e que interagem no comportamento das pessoas.

O estudo de caso aqui apresentado pretende contribuir nessa abordagem ao exemplificar a aplicação de uma ferramenta oriunda do campo teórico-disciplinar da psicologia ambiental para investigar expectativas e demandas presentes na dinâmica relacional pessoa-ambiente e assim proporcionar informações relevantes para que arquitetos possam redesenhar lugares e recintos com a garantia de obter um melhor desempenho ambiental.

\section{MATERIAIS E MÉTODOS}

A pesquisa foi realizada em março de 2017 em duas classes do curso técnico de Design de Interiores do campus Jacareí do IFSP, em um universo de 45 pessoas. Não houve identificação do respondente e nem limitação de respostas. As perguntas foram do tipo abertas e específicas de modo a facilitar o entendimento do usuário e a captação de uma diversidade maior de respostas (atributos diretos ou insinuados) relatadas. Surveys semiestruturados, são considerados inviáveis a este tipo de abordagem que deve apreender sentimentos.

O enfoque da pesquisa é captar níveis de adaptabilidade e conformidade do ambiente às necessidades do público usuário aqui considerando tanto os ambientes internos (salas, circulações) quanto externos (jardins, pátio). Para isso, adotou-se aqui a ferramenta denominada de "qualificativos associados" ou "constelação de atributos", desenvolvida por Ekambi-Schimidt (1974) a partir de estudos pioneiros conduzidos por Abraham A. Moles (1968) da Escola de Estrasburgo (França). O conceito teórico formulado busca isolar e analisar variáveis psicológicas (atributos) envolvidas no processo cognitivo que em seguida são sistematizadas e hierarquizadas em categorias distintas com base em duas realidades que perfazem a técnica investigativa: o confronto entre o objeto tangível (ambiente escolar) e o sujeito social (aluno) buscando levantar correlações e afetividades ligados às sensações geradas por esta relação.

O método prevê perguntas-chave que acionam mecanismos mentais ligados a consciência perceptiva. Assim, foi requisitado aos respondentes que pensassem o tema da "escola" em princípio de forma genérica e, depois, naquela experienciada cotidianamente, buscando identificar elos afetivos ou injunções que poderiam estar impactando sua usabilidade. Os respondentes são, por este modo, estimulados a descrever "quais" seriam esses elementos ou elos que promovem apreço ou desapreço pelo ambiente vivido.

A primeira pergunta, que remete ao campo imaginário, visa captar desejos e anseios afetos a uma escola que, no seu ponto de vista, Ihe causassem profunda agradabilidade: Que imagens ou ideias lhe vêm à cabeça quando você pensa numa escola? O objetivo é levantar percepções de uma concepção ideal de escola que, segundo Ekambi-Schimidt (op. cit.) vem acionar mecanismos culturais e de memória ainda que condicionados por estereótipos pré-concebidos oriundos da massificação entronizada pela mídia e seus modelos de sociabilidade, o que exige uma filtragem feita na etapa seguinte. A segunda pergunta, feita na sequência, remete a impressão do ambiente escolar em uso: Que imagens ou ideias the vêm à cabeça quando você pensa nesta escola? A indagação capta uma opinião concreta devidamente filtrada de idealizações impessoais que permearam a resposta anterior. 
O conjunto de respostas é depois compilado e sistematizado gerando tabelas onde atributos são relacionados por categorias especificas observando as maiores ocorrências. Em correspondência as "distâncias psicológicas" são calculadas por modelo matemático (Equações 1 e 2) estabelecendo a configuração própria das constelações consistindo numa visão geométrica do fenômeno observado. A ferramenta encontra-se atualmente informatizada e disponível em portal de acesso público: http://www.fec.unicamp.br/ confterm/.

As variáveis encontradas são graficamente representadas com base na definição da probabilidade ( $\mathrm{Pi})$ de associação do atributo (i) com o objeto avaliado que vem gerar a "distância psicológica" (D) em "cm" que representa as conexões de cada atributo ao objeto, descritas respectivamente nos modelos abaixo:

$$
P i=n i x \frac{100}{N} \quad \text { Equação } 1 \quad D=\frac{1}{\log P i} \quad \text { Equação } 2
$$

Onde: $\quad \mathrm{Pi}=$ probabilidade de associação do atributo $\mathrm{i}$

$\mathrm{D}=$ distância psicológica do atributo $(\mathrm{cm})$

$\mathrm{ni}=$ número de aparições do atributo $\mathrm{i}$

$\mathrm{N}=$ total de respostas

Uma cadeia de atributos é assim gerada e sistematizada permitindo visualizar aquelas de maior ocorrência no universo pesquisado correspondendo no gráfico às menores conexões objeto-atributo, consequentemente revelando as maiores demandas acumuladas. Ao contrário, as maiores conexões revelam distanciamento e pouca atratividade àquele atributo não angariando uma percepção maior de importância no contexto de sua usabilidade. Os qualificativos que emergem do processo gráfico dão margem a análises relacionais correlacionados às distintas visões da realidade objetiva e subjetiva que ali decorrem. Cada categoria de análise recebe um código cromático, cores estas que se repetem nos gráficos. Duas constelações de atributos (real e imaginária) são assim geradas e quando correlacionadas permitem mapear a percepção ambiental do usuário e assim estimar a adequação do ambiente a padrões de agradabilidade aqui considerado em um contexto amplo de conforto ambiental.

\section{RESULTADOS E DISCUSSÕES}

Os resultados apresentados permitiram materializar diagramas que oferecem uma visualização do nível de ajustamento pessoa-ambiente vivido dos interiores às áreas livres. As respectivas distâncias psicológicas, correspondendo as barras nos diagramas refletem essa qualidade de maior ou menor aproximação psicológica sugerindo os níveis de atratividade levantados. Totalizou-se 6 (seis) diferentes categorias de atributos levantados que correspondem a prioridade de preferências pelos alunos na análise geral. São as categorias de arquitetura e design, conforto ambiental, ergonomia, funcionalidade, manutenção e tecnologia. Outras preferências por terem sido ínfimas na preferência geral, foram aqui descartadas. A aplicação do modelo, que se inicia com as planilhas (Tabelas 1 e 2) se conclui, na sequência, com os Diagramas (1 e 2) permitindo uma representação da percepção ambiental e a visualização dos qualificativos ligados a essa ambiência imaginada. O comprimento das barras ilustra o maior/menor distanciamento aos atributos ou demandas simbolicamente geradas. 
Niemeyer, C. A. C.

Tabela 1 - atributos associados ao ambiente escolar imaginário

TABELA DE ATRIBUTOS ASSOCIADOS AO AMBIENTE IMAGINÁRIO

LOCAL DE PESQUISA: Percep̧̧a ambiental de Salas de Aula no Campus jacarei do IFSP

\begin{tabular}{|c|c|c|c|c|}
\hline CATEGORIAS & $\begin{array}{c}\text { ATRIBUTOS ASSOCIADOS AO } \\
\text { AMBIENTE }\end{array}$ & $\begin{array}{l}\text { QUANT. } \\
\text { OCORRENCIAS }\end{array}$ & CLASSIFICAÇĀo & $\begin{array}{l}\text { DIST. } \\
\text { PSICOLOGICA }\end{array}$ \\
\hline \multirow{6}{*}{$\begin{array}{l}\text { Arquitetura e } \\
\text { Design }\end{array}$} & Ambiente convidativo & 14 & 3 & 1 \\
\hline & Comunicaçäo Visual & 12 & 4 & 1.1 \\
\hline & Ambiente inspirador & 7 & 6 & 1.4 \\
\hline & Espaços de Permanéncia & 6 & 7 & 1.6 \\
\hline & Sala ambiente & 3 & 9 & 3.1 \\
\hline & Cantina agradável & 2 & 10 & 6.7 \\
\hline & SUBTOTAL & 44 & & \\
\hline \multirow{6}{*}{$\begin{array}{l}\text { Conforto } \\
\text { Ambiental }\end{array}$} & Conforto acústico & 17 & 1 & 0.93 \\
\hline & Conforto térmico & 17 & 1 & 0.93 \\
\hline & lluminação adequada & 15 & 2 & 0.98 \\
\hline & Boa ventilaçăo & 8 & 5 & 1.3 \\
\hline & Árvores e jardins & 5 & 8 & 1.8 \\
\hline & Materiais sustentáveis & 2 & 10 & 6.7 \\
\hline \multicolumn{2}{|r|}{ SUBTOTAL } & 64 & & \\
\hline \multirow{2}{*}{ Ergonomia } & Acessivel & 6 & 7 & 1.6 \\
\hline & Carteiras confortáveis & 6 & 7 & 1.6 \\
\hline \multicolumn{2}{|r|}{ SUBTOTAL } & 12 & & \\
\hline \multirow{3}{*}{ Funcionalidade } & Armários individuais aos alunos & 6 & 7 & 1.6 \\
\hline & Ar condicionado & 5 & 8 & 1.8 \\
\hline & Elevador & 2 & 10 & 6.7 \\
\hline \multicolumn{2}{|r|}{ SUBTOTAL } & 13 & & \\
\hline \multirow{2}{*}{ Tecnologia } & Mais tecnologia em classe & 7 & 6 & 1.4 \\
\hline & Controles da iluminação & 2 & 10 & 6.7 \\
\hline \multicolumn{2}{|r|}{ SUBTOTAL } & 9 & & \\
\hline \multicolumn{2}{|c|}{ TOTAL DE RESPOSTAS } & 142 & & \\
\hline \multicolumn{2}{|c|}{ TOTAL DE ENTREVISTADOS } & 45 & & \\
\hline
\end{tabular}

Fonte: $\mathrm{O}$ autor

Diagrama 1 - Constelação de Atributos referente a escola imaginária

Arquitetura Design 1 Contorto Ambiental (1) Ergonomia (1) Funcionalidade Tecnologia

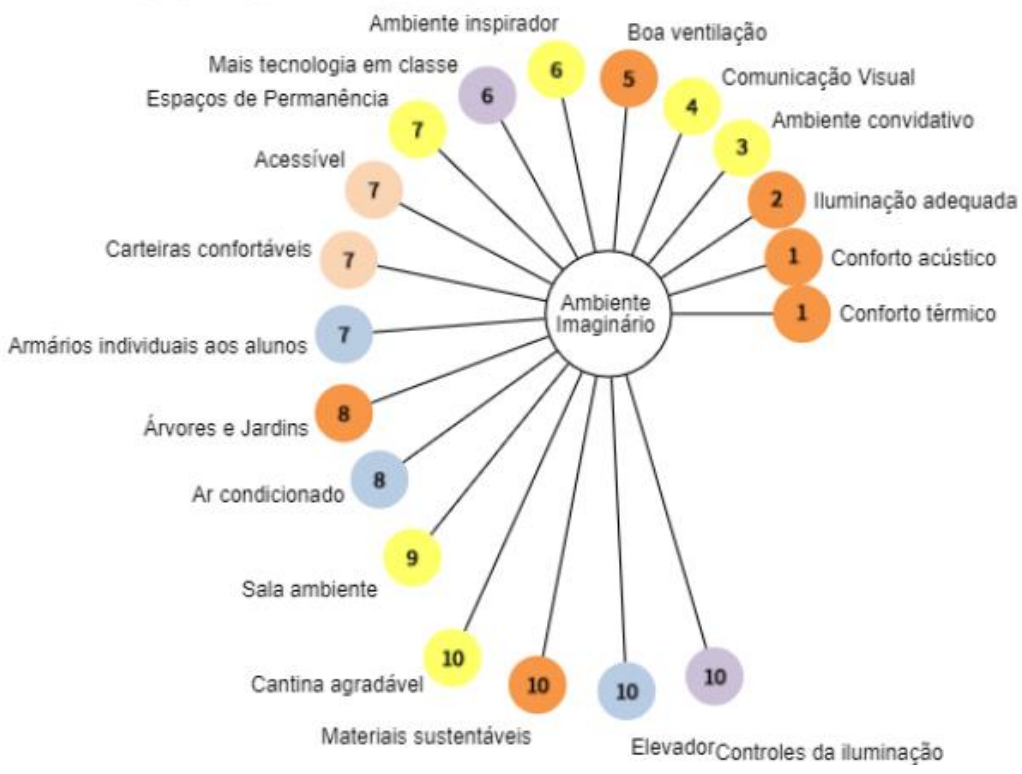

Fonte: $\mathrm{O}$ autor 
Niemeyer, C. A. C.

Tabela 2 - atributos associados ao ambiente escolar real

TABELA DE ATRIBUTOS ASSOCIADOS AO AMBIENTE REAL

LOCAL DE PESQUISA: Percep̧̧a ambiental de Salas de Aula no Campus jacarei do IPSP

\begin{tabular}{|c|c|c|c|c|}
\hline CATEGORIAS & $\begin{array}{c}\text { ATRIBUTOS ASSOCIADOS AO } \\
\text { AMBIENTE }\end{array}$ & $\begin{array}{l}\text { QUANT. } \\
\text { OCORRENCIAS }\end{array}$ & CLASSIFICAÇĀo & $\begin{array}{l}\text { DIST. } \\
\text { PSICOLGGICA }\end{array}$ \\
\hline \multirow{7}{*}{$\begin{array}{l}\text { Arquitetura e } \\
\text { Design }\end{array}$} & Areas livres nào exploradas & 8 & 3 & 13 \\
\hline & Ambiente pouco convidativo & 5 & 5 & 1.8 \\
\hline & Arquitetura fria & 5 & 5 & 1.8 \\
\hline & Bonita e bem organizada & 4 & 6 & 22 \\
\hline & Cantina desconfortável & 2 & 8 & 6.5 \\
\hline & Interiores escuros & 2 & 8 & 6.5 \\
\hline & Salas espaçosas & 2 & 8 & 6.5 \\
\hline & SUBTOTAL & 28 & & \\
\hline \multirow{6}{*}{$\begin{array}{l}\text { Conforto } \\
\text { Ambiental }\end{array}$} & Desconforto térmico & 31 & 1 & 0.74 \\
\hline & Desconforto acústico & 19 & 2 & 0.88 \\
\hline & Salas escuras a noite & 6 & 4 & 1.6 \\
\hline & Arborizada & 3 & 7 & 3 \\
\hline & $\begin{array}{l}\text { Excesso de insolação nas salas de } \\
\text { design }\end{array}$ & 3 & 7 & 3 \\
\hline & Boa luminosidade diurna & 2 & 8 & 6.5 \\
\hline & SUBTOTAL & 64 & & \\
\hline \multirow{7}{*}{ Ergonomia } & Carteiras desconfortáveis & 8 & 3 & 1.3 \\
\hline & Acessibilidade ruim & 6 & 4 & 1.6 \\
\hline & Boa acessibilidade & 5 & 5 & 1.8 \\
\hline & Piso escorregadio & 3 & 7 & 3 \\
\hline & Pranchetário desconfortável & 3 & 7 & 3 \\
\hline & Rampas cansativas & 3 & 7 & 3 \\
\hline & Carteiras confortáveis & 2 & 8 & 6.5 \\
\hline \multicolumn{2}{|r|}{ SUBTOTAL } & 30 & & \\
\hline \multirow{2}{*}{ Funcionalidade } & Ventiladores pouco eficientes & 8 & 3 & 1.3 \\
\hline & Falta elevador & 4 & 6 & 22 \\
\hline \multicolumn{2}{|r|}{ SUBTOTAL } & 12 & & \\
\hline Manutençă̊ & Ambientes limpos & 6 & 4 & 1.6 \\
\hline \multicolumn{2}{|r|}{ SUBTOTAL } & 6 & & \\
\hline \multicolumn{2}{|c|}{ TOTAL DE RESPOSTAS } & 140 & & \\
\hline \multicolumn{2}{|c|}{ TOTAL DE ENTREVISTADOS } & 45 & & \\
\hline
\end{tabular}

Fonte: O autor

Diagrama 2 - Constelação de Atributos referente a escola real

Arquitetura e Design 1 Conforto Ambiental (1) Ergonomia (1) Funcionalidade () Manutençăo

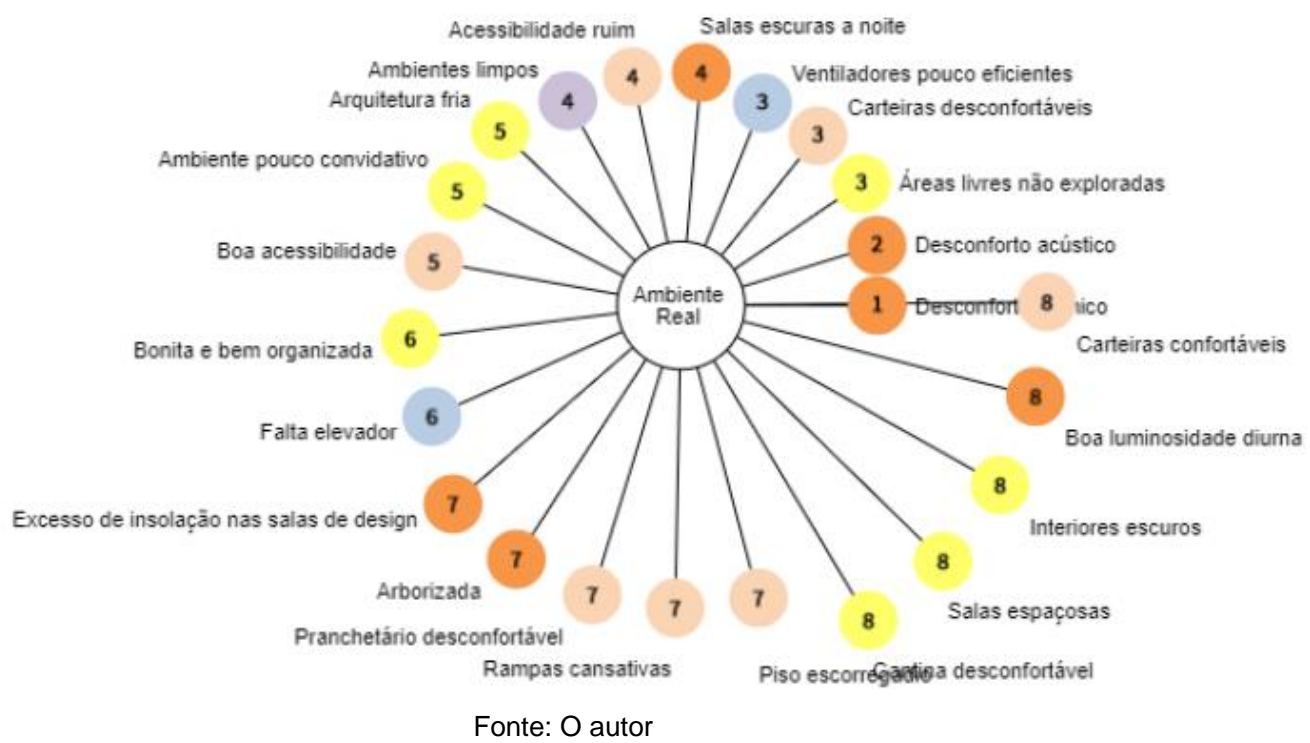

Fonte: $\mathrm{O}$ autor 
Os resultados da percepção gerada para a escola imaginária foram fortemente abalizados por expectativas ligadas a conforto ambiental, arquitetura e design e tecnologia (Diagrama 1). Era comum, nas respostas, se remeter, eventualmente, a concepções particulares de colégios de referência vivenciados in loco por alguns ou decerto assimilados por imagens da mídia, todavia, significantes pelo status de conforto que tais modelos sugerem à imaginabilidade do ambiente escolar que se deseja. A questão da tecnologia vista como essencial na escola imaginária, todavia não comparece na escola real (Diagrama 2), o que sugere satisfação pontual com o ambiente real. Confrontados os citados paradigmas de conforto ambiental citados na escola imaginária com a escola real, constata-se a ressurgência deles (acústico e lumínico), seguido por uma forte crítica associada a "áreas livres não exploradas", caracterizando uma eloquente demanda reprimida que clama pela requalificação das atuais áreas de permanência externas, o que, de fato, colide com o argumento da "ambientação agradável" lembrada na escola imaginária (Diagrama 1). Na sequência, atributos de ergonomia e funcionalidade exercem igual importância na percepção da escola real (Diagrama 2) indicando insatisfação com assentos e ventiladores, não suficientes para oferecer conforto.

A estética do ambiente imaginário recebe significativas citações como aquelas que lembram "ambientes convidativos" e "comunicação visual" que identificam ambientes estimulantes para o convívio com áreas de permanência agradáveis e confortáveis. Na leitura da escola real, atributos ligados a ambiência paisagística encontram-se mais distantes, com pouca empatia, assinalada como "fria" aferindo pouca atratividade geral. Aponta-se assim uma demanda negativa para aspectos ligados a ambientes de convívio na escola.

Os atributos levantados e sinteticamente analisados, são um retrato de expectativas que catalisam demandas cognitivas do grupo social avaliado com base na vivência experienciada no mundo real que o cerca. Aspectos essenciais como acessibilidade, qualificação estética e paisagística, manutenção, convivência, design e outros indicadores ergonômicos e funcionais, assinalam um norte ao pesquisador por permitir iluminar demandas cognitivas que traduzem o olhar particular do corpo discente sobre seu ambiente de convívio ao qual passa longas horas do dia. O método aqui ilustrado permite investigar a percepção de ambientes levantando demandas ocultas guardadas na consciência cognitiva de cada pessoa aguardando serem provocadas para virem à tona.

\section{CONCLUSÕES}

Procurou-se, nessa abordagem, avaliar a conformação ambiental com base na aplicação da metodologia de atributos induzidos ou constelação de atributos em duas turmas de alunos secundaristas de uma escola técnica servindo como estudo de caso na aplicabilidade do modelo de análise da percepção ambiental.

Os resultados permitiram aferir o desempenho ambiental e consequentes estimações envolvidas na percepção que os usuários fazem desses recintos tão presentes na sua vivência cotidiana. O método configura sua utilidade no oferecimento de novos diagnósticos comportamentais permitindo um olhar peculiar e determinante na avaliação da qualidade do lugar e na obtenção de dados topofílicos culminando na construção de diagramas afetivos que materializem de forma sensível o contexto relacional pessoa-lugar.

Assim como outras ferramentas da psicologia social e ambiental que permitem captar sentimentos e desejos relativos ao ambiente, a constelação de atributos se mostra eficaz para compor análises multimétodos em contextos de gestão participativa das informações de projeto, permitindo aferir graus de atratividade e empatia com coerência investigativa. Sem dúvidas, uma ferramenta que se soma a outras na produção de um saber sistematizado sobre a qualidade do lugar.

Por fim, salienta-se que o ensino público no Brasil sempre foi muito discutido por ilustres educadores na ânsia de se buscar uma melhor adequação das estruturas educacionais à nossa realidade social e ambiental, todavia nem sempre se assentou adequadamente o discurso da qualificação ambiental no processo de projeto, apesar de vastos estudos nesse sentido. Assim, podemos concluir que o projeto de ambientes de aprendizado quando assimilam aspectos relacionais pessoa-ambiente tendem a oferecer um impacto emocional bastante positivo a estudantes e funcionários, contribuindo indiretamente para uma adaptação mais envolvente ao espaço escolar, estimulando seu aprendizado. A arquitetura entra com novas estratégias metodológicas nesse contexto voltado à qualidade dos ambientes de aprendizagem, agregando novos caminhos e perspectivas ao processo de projeto de ambientes educacionais.

\section{REFERÊNCIAS}

BASTOS, M.A.J. A Escola-Parque: ou o sonho de uma educação completa (em edifícios modernos). Pini Revistas. AU. Edição 178 - Janeiro de 2009. Disponível em: http://au17.pini.com.br/arquitetura-urbanismo/178/a-escola-parque-ou-osonho-de-uma-educacao-completa-em-122877-1.aspx. Acesso em: 20/12/2017. 
BARKER, R.G. (1968). Ecological psychology. Stanford: Stanford, University Press, 1968.

BESTETTI, M.L.T. Ambiência: espaço físico e comportamento. Rev. Bras. Geriatr. Gerontol. vol.17 no.3 Rio de Janeiro jul./set. 2014. Disponível em: http://dx.doi.org/10.1590/1809-9823.2014.13083. Acessado em: 09/10/2017

CORRAL-VERDUGO, V, Psicologia Ambiental: objeto, "realidades" sócio-físicas e visões culturais de interações ambiente-comportamento. Psicol. USP vol.16 no.1-2 São Paulo, 2005.

DEL RIO, V.; DUARTE, C.; RHEINGANTZ, P. (Org) Projeto do lugar: colaboração entre psicologia, arquitetura e urbanismo. Rio de Janeiro: UFRJ-Proarq/Contracapa, 2002, $392 \mathrm{p}$.

EKAMBI-SCHMIDT, J. La percepción del hábitat. Barcelona: G. Gili, 1974.

ELALI, G.A. Relações entre comportamento humano e ambiência: uma reflexão com base na Psicologia Ambiental. UFRN (1998). Disponível em: https://0602.nccdn.net/000/000/04e/cb0/Artigo-GLEICE-ELALI-FULL.pdf. Acessado em: 18/11/2017.

FONSECA, J.F.; RHEINGANTZ, P.A. O ambiente está adequado? Prosseguindo com a discussão. Produção, v.19, no. 3. São Paulo, Set/dez 2009, p 502-513.

GRAÇA, V.A.C.; KOWALTOWSKI, D.C.C.; PETRECHE, J.R.D. O Projeto Axiomático. In: KOWALTOWSKI, D. et al. O processo de projeto em arquitetura. São Paulo: Oficina de Textos, 2011, pg. 151-180.

MELO, L.G. Arquitetura escolar e suas relações com a aprendizagem. Dissertação de Mestrado. UERJ-FCP, 2012.

MONT'ALVÃO, C.; VILLAROUCO, V. (Org) Um novo olhar para o projeto: a ergonomia no ambiente construído. Teresópolis (RJ): 2AB, 2011.

MONTANER, J.M. Después del movimento moderno. Barcelona: Gili, 1993.

MOREIRA, D.C.; KOWALTOWSKI, D. O programa arquitetônico. In: KOWALTOWSKI, D. et al. O processo de projeto em arquitetura. São Paulo: Oficina de Textos, 2011, pg. 101-108.

PINHEIRO, J.; GUNTHER, HARTMUT, G. (Org) Métodos de Pesquisa nos Estudos pessoa-ambiente. São Paulo: Casa do Psicólogo, 2008, 396 pg.

SOUTO, M. A Escola: este microcosmo... Editoriais e Opinião. Ponto Final. Disponível em: https://opiniaopontofinal.wordpress.com/2014/11/23/a-escola-este-microcosmo/. Acessado em 28/12/2017.

TUAN, Yi-fu. Topofilia - um estudo da percepção, atitudes e valores do meio ambiente. São Paulo: DIFEL, 1980.

VASCONCELOS, C.S.F. et al. Contribuição da Psicologia Ambiental na análise ergonômica do ambiente construído. Revista Ação Ergonômica. Rio de Janeiro: ABERGO/UFRJ, volume 5, no. 3, p.14-20, DEZ/2010.

ZEVI, B. Saber ver a arquitectura. Lisboa: Arcádia, 1977, 219 pg.

NOTA DO EDITOR (*) O conteúdo do artigo e as imagens nele publicadas são de responsabilidade do(s) autor(es). 